\title{
DESCENTRALIZAÇÃO DA VIDA LITERÁRIA, CONSTRUÇÃO DE AUTORIA TEÓRICO-CRÍTICA NA PERIFERIA DO SISTEMA CULTURAL E DE CIRCULAÇÃO LITERÁRIA
}

\author{
DECENTERING LITERARY LIFE, BUILDING UP THEORETICAL-CRITICAL \\ AUTORSHIP ON THE PERIPHERY OF THE CULTURAL SYSTEM AND ON THE \\ MARGINS OF LITERARY CIRCULATION
}

Fábio Almeida de Carvalho ${ }^{1}$

\begin{abstract}
RESUMO: Tendo como esteio um tipo de abordagem que oscila entre o depoimento e a subjetividade, por um lado, e a análise crítica e objetiva, por outro, o presente ensaio discute a problemática da descentralização da vida literária brasileira e relaciona essa relevante questão do campo dos estudos literários na atualidade com o fazer-saber teóricocrítico realizado na periferia do sistema cultural nacional e mundial, e, ainda, com a questão da circulação literária. O objetivo último do artigo é o de propor alguma base de ação para o trabalho e a atuação teórica e crítica no campo dos estudos literários produzidos na periferia do grande sistema literário e cultural.
\end{abstract}

PALAVRAS-CHAVE: Descentralização da vida literária; teoria; crítica; autoria.

\begin{abstract}
Based on an approach that oscillates between testimony and subjectivity, on the one hand, and critical and objective analysis, on the other, this essay discusses the issue of decentralization of Brazilian literary life and relates this relevant issue in the field of literary studies nowadays with the theoretical-critical know-how carried out on the periphery of the national and world cultural systems and also with the issue of literary circulation. The ultimate goal of this article is to propose some basis of action for the reflection on theoretical and critical questions in the field of literary studies produced on the periphery of the mainstream literary and cultural system.
\end{abstract}

KEYWORDS: decentering literary life; theory; criticism; authorsip.

\footnotetext{
${ }^{1}$ Universidade Federal de Roraima - UFRR, Programa de Pós-Graduação em Letras, PPGSOF, Instituto Insikiran de Formação Superior Indígena, Boa Vista, Roraima, Brasil; CNPq; FAPERJ; https://orcid.org/00000002-1986-6782 ; fabioalmeidadecarvalho@yahoo.com.br
} 
Numa das mais incisivas narrativas da safra existencialista que impactou a tradição literária romanesca do Ocidente de meados do século XX, Jean Baptiste Clemence, protagonista de A queda ([1956]1986), se notabilizou pelo modo de narrar a própria história para um ouvinte desconhecido num bar de fama duvidosa, no cais do porto de Amsterdã. Nesse contundente romancinho, o escritor franco-argelino Albert Camus, ganhador do Nobel de 1957, encena parte da vida de um ex e bem integrado integrante do sistema judiciário francês que, depois de casualmente presenciar uma mulher saltar de uma ponte e morrer afogada nas águas do rio Sena, é acometido por paulatina tomada de consciência em relação ao caráter superficial e farsesco de sua vida privada e institucional.

Incomodado por nada ter feito para impedir o suicídio de que foi testemunha única e pela sensação de que podia ter salvado a mulher, o advogado parisiense desperta para a realidade de que sua bem sucedida vida pública era vazia e destituída de profundidade. O episódio o faz atinar para a verdade de que os gestos e atos que tanto o reputavam no circuito social que integrava eram, em verdade, gestos de fachada, atos para a opinião pública ${ }^{2}$. Os eventos da fatídica noite causam grave perturbação em Jean Baptiste que acaba por largar a vida de pompa e aclamação que levava no ambiente luxuoso de Paris para trabalhar como advogado para vagabundos, marinheiros e frequentadores suspeitos do bar Novo México, onde reside desde então.

$\mathrm{Na}$ fortuna crítica do incensado romance de A. Camus fez lastro a chave de interpretação em que, num nível, se destaca a sondagem da alienação humana face ao comezinho do cotidiano, e, noutro, a compreensão de que, ao narrar o processo da crise, ou mais precisamente da queda, o filósofo-romancista invoca, em termos seculares, o problema fundador da Queda do Homem. ${ }^{3}$ Conforme o funcionamento dessa chave de leitura e interpretação, a moral da história pode ser condensada no ensinamento de que, cada vez em que cresce no indivíduo a consciência de si e que, por conseguinte, ele decide exercer o direito à liberdade de lutar por aquilo que considera justo, há sempre uma sentença, uma punição que se lhe segue. Daí, resulta a alegoria de que, perante a necessidade de conviver em profundidade com as próprias verdades, os homens costumam experimentar a vertigem do abismo - algo que socialmente é sempre bastante perigoso.

E, tal qual ocorre com o inclemente Jean Baptiste, homens comuns soem também ficar temporária e potencialmente perturbados por processos de tomada de consciência. Por vezes, o estado de tensão é constante e o mal-estar pode ocorrer devido à simples vontade de experimentar a liberdade de pensar e do consequente desejo de problematizar as armadilhas ideológicas que nos interpelam continuamente e de variadas maneiras; mas esses momentos perturbadores também costumam se manifestar quando o exercício da (auto)crítica aguça a percepção de nossa quase sempre beata adaptabilidade em relação a variados fenômenos de ampla aceitação nas esferas privada, pública e institucional.

Não obstante, quando momentaneamente se agudiza o senso de absurdo da realidade e somos de alguma forma constrangidos a questionar certos aspectos das dimensões éticas,

\footnotetext{
${ }^{2} \mathrm{O}$ aspecto "bom moço" dos ritos do convívio social de Jean Baptiste Clemence era tão afetado que era capaz de fazê-lo ajudar um cego a atravessar uma rua movimentada e, chegando do outro lado da via, tirar a cartola para saudá-lo com salamaleques e rapapés ostensivos.

${ }^{3} \mathrm{Na}$ tradição bíblica, a Queda do Homem é também chamada de Pecado Original e diz respeito ao momento em que Adão e Eva desobedeceram a Deus, contaminando, por conseguinte, a humanidade. Filosoficamente, o problema da Queda do Homem corresponde à tópica do despertar da consciência e da personalidade humana.
}

Rev. Bras. Lit. Comp. Niterói, v. 22, n. 39, pp. 26-36, jan. /abr. 2020 
estéticas, políticas e poéticas do nosso savoir-faire, os homens costumam, grosso modo, fazêlo de maneira bem menos radical do que Jean Baptiste Clemence. Assim, sói às vezes que, depois de acumular anos de ativismo num determinado espaço institucional, alguns são tocados ora pelo vazio e a angústia do beco sem saída, ora pela sensação de desorientação, típica do labirinto. Aqueles que simplesmente ignoram ou que dizem não passar por situação similar em algum momento da existência são, em geral, definidos como "bem-integrados", enquanto aqueles outros que assumem a perdição como tentativa de se encontrar são correntemente catalogados como "mal enquadrados" e/ou "mal-integrados" (Flusser, 2008, s. p.).

Para os que são acometidos pelo sentimento de fechamento do beco ou pela sensação de multiplicidade do labirinto - por excesso de clausura ou abertura em demasia - não resta senão dar um passo atrás de si mesmos para tentar compreender um cadinho mais sobre o que de fato está fazendo ao fazer o que faz do modo como faz. Nesse ambiente, o homem atordoado dispõe de alguma condição de qualidade para questionar, por exemplo, automáticas reações acolhedoras e conformadas de "tópicos desistoricizados oriundos de sociedades de prestígio". 4 A condição propicia alçar voo com perspectiva um pouco ampliada sobre as relações de poder que cada homem exerce e que é exercida sobre cada um no âmbito de um determinado quadro institucional e de uma dada formação discursiva.

Não obstante, o passo atrás é sempre incerto devido ao fato de que, se por um lado, ajuda a passar em revista certas convicções assumidas pela maioria com cândida naturalidade, por força daquilo que as modernas teorias do comportamento definem como "efeito manada", por outro lado, pode expor aspectos denunciadores das limitações e dos alcances, não apenas dos sentidos das práticas e ritos institucionais de que participamos, mas também de certos aspectos das nossas vidas particulares e privadas. No limite, tal situação também pode gerar consequências não completamente controladas pelas implicações pressupostas no jogo enunciativo mantido pelas posições sociais que ocupamos e assumimos. E, demais, não obstante exigir uma dose generosa de compromisso com a verdade, tal empreitada em geral não tem como assegurar nem garantir êxito, além de ampliar as possibilidades de destruição de certos laços sociais.

Pelo que atrás foi dito, o leitor já deverá ter desconfiado que as considerações substanciadas neste ensaio foram produzidas sob uma espécie de "sensação de desorientação desperta", que teima em dar cabriolas no pensamento de todo sujeito que "se sente essencialmente perdido e que, ao se dar conta disso, procura [desesperadamente] encontrar-se" (Flusser, 1998, s. p.). O clima de desorientação é conformador da expressão, da forma e do conteúdo da presente elocução, que tem nas questões da função da Crítica e da Teoria Literária, em tempos de prevalência epistemológica dos Estudos Culturais, e da autoria, em tempos de dominância do modelo da diversidade, com destaque para a questão das autorias indígenas, seus objetos derradeiros de interesse e de (auto)análise.

A discussão gira em torno das contradições peculiares à existência de um professor de literatura que trabalha naquilo que se costuma definir como a periferia da produção de bens culturais e que, há mais de três décadas, vem carreando sua energia para realizar atividades

\footnotetext{
${ }^{4}$ Essa é uma dimensão importante para a estrutura do argumento que sustenta o presente ensaio: nesse passo, tenho em mente aquele estado de coisas de que tratam Pierre Bourdieu e Loïcq Vacquant no ensaio intitulado Sobre as artimanhas da razão imperialista (Revista de Estudos Afro-asiáticos, 24, nº.1, 2002, p. 15-33), no qual os autores discutem o modo por que a agenda cultural do circuito universitário americano, exportador do modelo da diversidade, foi assimilado de forma espontânea e beata em diferentes latitudes do planeta, mas sobretudo no Brasil, e denunciam que "realidades complexas e controvertidas de uma sociedade histórica particular [a sociedade estadunidense] são tacitamente constituídos como modelo e medida de todas as coisas"; eles acrescentam que, por intermédio do martelamento acadêmico e midiático, "termos isolados com aparência técnica que [...], pelo fato de condensarem ou veicularem uma verdadeira filosofia do indivíduo e da organização social, adaptam-se perfeitamente para funcionar como verdadeiras palavras de ordem”.
}

Rev. Bras. Lit. Comp. Niterói, v. 22, n. 39, pp. 26-36, jan. /abr. 2020 https://doi.org/10.1590/2596-304X20202239fac 
voltadas para a formação de leitores de textos literários em perspectiva comparada; demais, também vem-se empenhando em contribuir para o aprofundamento do pensamento crítico e teórico sobre os problemas atinentes à literatura produzida na fronteira vazada do extremo norte da América do Sul, em sua dinâmica relacional com as culturas brasileira, venezuelana e guianense, e sobre as formas de permanência e atualização das textualidades indígenas, com o objetivo de contribuir para a compreensão dos papeis desempenhados pelas produções culturais oriundas desse local, no concerto das literaturas brasileira, americana e, enfim, da literaturamundo.

Essas condições, quando adjungidas a fenômenos como o radical questionamento dos cânones literários nacionais e das noções de centro-periferia, à consciência da confluência de muitas línguas num mesmo território e das múltiplas migrações culturais, à literatura de viagem, à emergência de diversas vozes subalternizadas, com destaque para a literatura indígena, ao caráter multinacionalizado da hodierna indústria editorial, à emergência da necessidade de delineamento da participação das literaturas menores e não ocidentais no concerto das literaturas nacionais e da literatura-mundo, dentre outros aspectos da questão, tornam o compromisso de assumir uma posição autoral no campo da Teoria e da Crítica literárias um desafio bastante instigante.

Esse é o ponto de apoio e de expansão da presente reflexão, que oscila entre depoimento e subjetividade, por um lado, e análise crítica e objetiva, por outro - na tentativa de combinar os inconciliáveis da narrativa pessoal e da análise crítica objetificada. Com essa atitude, intentamos conscientemente nos inserir numa tradição discursiva que floresce com vigor em nossos dias e que pode ser caracterizada, conforme define Zhang Longxi (2017, p. 56), pela necessidade de que "críticos oriundos de diferentes tradições culturais [envidem esforços] para defender a canonicidade e o valor dos melhores trabalhos de suas tradições e nos convencer porque um trabalho particular é valioso e vale a pena ser lido além de sua cultura original".

Desse modo, ainda que o objetivo do trabalho que realizamos seja discutir questões de caráter eminentemente teórico e crítico - que envolvem diálogos interculturais, circulação literária, cânone, noções de autoria em tempos de diversidade, dentre outros aspectos do mesmo campo e tradição discursiva - o elemento autobiográfico desempenha importante papel na enunciação do presente ensaio. Disso decorre, em certa medida, o rompimento da dissociação entre vida pessoal, dotada de densidade empírica, e a função autoral, institucionalizada pela impessoalidade da escrita, tal e qual preconizado por Foucault ([1968]2009). Assim, sem abdicar inteiramente de alguma noção de verdade relacionada à cientificidade própria do campo dos estudos literários, a enunciação que segue também se assenta e busca algum equilíbrio sobre uma base existencial e empírica.

Mas a noção de autoria constitutiva da presente enunciação não tem a pretensão de dar como garantia última alguma verdade empiricamente baseada: mais que qualquer outra coisa, ela antes se propõe a fazer uma provocação, como sói ocorrer em diversos gêneros da escrita do campo das humanidades na contemporaneidade, que se apresentam "na forma de um jogo que brinca com a noção de sujeito real”. (Klinger, 2012, p. 40). Não se trata, pois, da tentativa de espetacularização da subjetividade no campo da prosa acadêmica, mas sim do compromisso de pensar e refletir a partir de uma vivência que, em larga medida, é constrangida por um conjunto de coordenadas da vida prática e da atividade teórica que determinam a ação e a reação daqueles que atuam num determinado campo do conhecimento e num determinado espaço institucional.

Diante de certa tendência típica de nossos dias que é propícia a radicalizar e tornar imperativos os princípios e a ordem do politicamente correto ao campo da criação artística e literária, assumir atitude crítica e teórica que se esteia em protocolos de análise literária se tornou atitude incompreendida e, por vezes, até mesmo intolerante. A emergência e o grande 
fortalecimento das políticas de identidades ocorrido no âmbito do universo acadêmico brasileiro nas últimas décadas podem ser entendidos como sintoma mais ostensivo desse estado de coisas.

É, pois, tendo como pano de fundo esse cenário (que quase aboliu a apreciação da literatura enquanto tal na leitura e interpretação de obras literárias, e em que o "juízo de valor é algo que estudiosos literários tendem a evitar na corrente acadêmica ambiente, particularmente nas universidades estadunidenses e europeias, onde os valores são reconhecidos como contingentes a fatores econômicos, sociais e políticos, e considerados elitistas, politicamente incorretos e até mesmo ideologicamente repressivo" (Longxi, 2017, p.54), que a presente enunciação se assenta.

Temos consciência de que o enfrentamento aberto dessas questões - e que envolvem o compromisso de opinar tanto sobre as produções tidas como periféricas quanto sobre as realizações de populações definidas como minoritárias - pode acarretar situações nada confortáveis e, por vezes, mesmo desagradáveis. Afinal, trata-se de verdadeiro campo minado, em que são comuns posições que não apenas combatem, por exemplo, um turbante ornando a cabeça de uma mulher branca - porque supostamente constitui "apropriação indevida da cultura negra" -, mas que também defendem que "só negro entende coisa de negro", "só índio entende coisa de índio", etc., etc. E, nesse sentido, que recusa e escamoteia o jogo corrente de relações da vida, de "relações que se dão entre uns e outros, jamais entre os mesmos", só branco pode falar de branco, só negro pode falar de negro, só índio pode falar de índio. ${ }^{5}$

Corroborando (e adaptando para o chão do nosso caso) a posição de Antonio Risério (2012, p. 13 e segs.), um polêmico e tenaz intelectual baiano que já enfrentou tanto a questão das textualidades não ocidentais quanto à questão racial no Brasil, também não acho que por não ter nascido em Roraima não possa discutir a cultura local, assim como por não ser índio esteja eu impedido de discutir a questão da arte verbal indígena enquanto componente da cultura literária brasileira e humana. ${ }^{6}$ Muito menos considero com falsa afetação à possibilidade de estar "colaborando para o genocídio das culturas indígenas", pelas e com as quais trabalho há quase duas décadas.

\footnotetext{
${ }^{5}$ Discutindo a questão, a crítica estadunidense Marjorie Perloff (2018) afirma que "O multiculturalismo exerceu um efeito terrível sobre nossa poética. Se não se pode criticar um poeta afro-americano ou latino, tampouco se pode criticar um poeta branco, e isso elimina a possibilidade de um debate consistente. A ideia de que se deve sempre ter um representante de cada extrato racial e/ou social - um latino, um índio (ou americano nativo), uma afro-americana, uma lésbica sino-americana - foi por demais destrutiva. Não que não haja excelentes poetas nessas minorias. Mas não se pode forçar o interesse. Além disso, o multiculturalismo teve um efeito ruim também sobre o multinacionalismo - ou seja, nos Estados Unidos, o interesse pela poesia de outros é muito reduzido. Não se falam outras línguas e o termo "poesia estrangeira" é algo dúbio. [...]."

${ }^{6}$ Recentemente, dois autores, dentre outros, enfrentaram a questão de modo exemplar: o primeiro, Antonio Risério (2012, p. 13-15), bom conhecedor da situação do debate intelectual no Brasil, afirma que "a discussão e o debate estão cada vez mais maldito e suspeito: [...] não há lugar para a crítica, só para a adesão ou a maledicência. [...] A quase totalidade das pessoas que falam em diálogo, nele, de fato, não acreditam. Se crítico feministas, sou machista, se não gosto de alguma manifestação popular, sou elitista. Se invisto contra o neopentecostalismo, sou o demônio. Se tenho restrições ao movimento negro, sou racista. [Se tenho restrições ao movimento indígena, sou anti-indígena, poderia acrescentar de minha lavra]. E assim por diante. Vivemos dias de intolerância, indignações fáceis, sensibilidade neurótica a desvios e dissensões". O segundo: entrevistado pela jornalista Mirella Nascimento, da Folha de São Paulo, em 24/05/2018, ao ser indagado se já teria sido questionado pelos negros de seu país quanto ao seu lugar de fala, pelo fato de ser branco, com a agudeza que lhe é peculiar, o escritor moçambicano Mia Couto respondeu: "Esse é um debate novo, mesmo no Brasil. É uma coisa que vocês estão a importar de algum lugar, não sei de onde, mas desconfio. Mas há escritores negros que se colocam em posição de brancos. Aliás, se a escrita for interrogada desse ponto de vista do lugar de fala, ela morre. Eu só escrevo porque eu viajo para outros. Eu sou mulher, eu sou criança, eu sou velho, eu sou outros quando eu escrevo. Se eu só posso escrever naquela competência do meu lugar de fala como compete, eu só falo sobre mim. Então, o que cria a literatura é capacidade de ser outro."
}

Rev. Bras. Lit. Comp. Niterói, v. 22, n. 39, pp. 26-36, jan. /abr. 2020 https://doi.org/10.1590/2596-304X20202239fac 
Entretanto, é bom nunca esquecer que a língua anônima do povo afirma que "o seguro morreu de velho...". Mas não parece ser exatamente esse o caso, pois não se pretende fazer do exercício profissional espécie de fonte enunciadora de blandícias acolhedoras sussurradas aos ouvidos de donzelas de cachos e bandós, em detrimento do exercício da história, da teoria e da crítica literária. Diante, portanto, de um quadro como esse aqui esboçado, e que se caracteriza pela impossibilidade de ler todos os livros e todos os textos conformadores de uma determinada formação literária (seja ela ocidental, não-ocidental ou minoritária), e da certeza de que nem todos os livros e textos produzidos numa dada tradição discursiva são merecedores de canonização, cabe ao crítico buscar contribuir para uma expansão menos "selvagem" de artefatos literários oriundos de diferentes ecossistemas culturais e que circulam pelo mundo, mediante o empenho em estabelecer o reconhecimento daquelas obras de alto valor literário oriundos da tradição discursiva particular em que atua. ${ }^{7}$

E, sendo assim, não podemos a essa altura negar que partilhamos a concepção alegórica de A. Camus, que insistia em que, ao procurar incessantemente o sentido da existência numa vida carente de sentido, almejar a liberdade e a felicidade somente se torna possível [ao homem] por meio da rebelião. Não sei se exatamente... "a felicidade", como propõe o pensador argelino; talvez mais provável que seja apenas a mera satisfação derivada do sentimento do trato assumido e a sensação de que o dever e compromisso com a crítica podem, em alguma medida, ser cumpridos.

\author{
II \\ Posso oferecer-lhe os meus serviços, meu \\ Senhor, sem me tornar inoportuno?
}

caro

Albert Camus, A queda

"Seja bem-vindo à terra de Makunaima", anunciava, com alguma estranheza, a placa que, à saída do aeroporto, saudou o futuro professor de literatura. Ela abria as portas da pequena e ainda enigmática capital estadual mais setentrional do Brasil, a mais distante de Brasília e a única localizada totalmente ao norte da linha do Equador. Recém graduado, migrava eu, naquele instante, do Nordeste para Roraima, movido pela vontade de fazer carreira como profissional da área de letras e de continuar aprofundando estudos no campo da literatura, mas também pela oportunidade de conseguir "algum trocado pra dar garantia".

Tenho de nesse passo confessar que, àquela altura, eu sabia pouquíssimo sobre Roraima como um todo, e menos ainda sobre as especificidades da cultura local; mas também sabia, todavia, que Macunaíma, o protagonista do romance homônimo de Mário de Andrade, era originário dessas terras, localizadas no extremo norte do Brasil e da América do Sul.

Não obstante, pouco demorou para que meus ainda limitados conhecimento sobre o heróisímbolo de Roraima e do Brasil fossem contraditados: na primeira tentativa, ainda acanhada e vacilante, de entabular diálogo e ampliar um pouco a zona de conhecimento proximal em relação às peculiaridades culturais das terras de Makunaima, a destra espalmada de uma pretensa autoridade em arte local me engasgou: “- Primeiro que não é 'Macunaíma' com "c" e com acento, é 'Makunaima', com "k" e sem acento; segundo, Mário de Andrade nem pisou em Roraima, e é por isso que o livro é tão distante da realidade dos índios daqui”. A esses senões,

\footnotetext{
${ }^{7}$ Da perspectiva de Zhang Longxi (2017, p. 54), cuja atuação se caracteriza pelo empenho em fortalecer a especificidade da leitura literária de textos literários, por um lado, e reconhecer a importância da participação das textualidades não ocidentais e das minorias no concerto da literatura mundo, por outro, "o juízo de valor é inevitável na leitura e apreciação de literatura".
}

Rev. Bras. Lit. Comp. Niterói, v. 22, n. 39, pp. 26-36, jan. /abr. 2020 https://doi.org/10.1590/2596-304X20202239fac 
outros foram imediatamente acrescidos: que "Macunaíma não é de Mário de Andrade..., é dos índios", designados de maneira genérica de "macuxis", e que "o escritor modernista de São Paulo plagiou Theodor Koch-Grünberg". 8

Como podes perceber, caro leitor, as ressalvas acima resumidas abordam vários e diferentes aspectos de uma ampla questão cujo cerne tem a ver com as questões da autoria e com a autoridade teórica e crítica: para começar, num nível mais baixo, a) elas buscam evidenciar os supostos 'erros' grafonéticos da nominalização do herói na rapsódia do escritor modernista; depois, b) elas seguem denunciando não apenas a inadequação do ambiente e do conteúdo do romance em relação à realidade dos índios de Roraima; c) mas também o desconhecimento de M. de Andrade da realidade roraimense; em seguida, em tom um pouco mais grave, d) questionam ainda a autoridade e a própria autoria da obra. Por fim, e) elas acusam o autor de Macunaíma, o herói sem nenhum caráter (1928 [2008]) de ser plagiário. ${ }^{9}$ A curiosa peça de valor judicativo reúne, cuidadosamente, as etapas de acusação, julgamento e veredito num mesmo apressado e superficial ato de julgamento crítico. ${ }^{10}$

A autoridade ou legitimidade do enunciador da sentença se alicerçava, primeiramente, sobre a suposta fortaleza da "experiência pessoal" da realidade de Roraima e se sustentava, por conseguinte, no pretenso valor inquestionável e absoluto do conhecimento adquirido de forma direta. E assim, por derradeiro, mediante a artimanha retórica que define a experiência empírica como fonte suprema da verdade, a peça analítico-judicativa conseguia a proeza de marcar um lugar devido no campo das atividades teóricas e críticas para o postulante à função de professor de literatura na recém criada Universidade Federal de Roraima: a condição de forasteiro e de não antropólogo que, antes de postular o direito a uma réstia de luz para aquecer o espírito ainda frio ao sol, teria muito que comer pela raiz. Assim, por derradeiro, a peça tinha a função explícita de demarcar os lugares de fala definidos para a cena enunciativa dos discursos sobre a arte no espaço cultural em tela.

A estratégia discursiva em causa é típica da resiliente tradição etnográfica do século XIX, que tanto impactou sobre o campo das humanidades, e que se peculiarizou por assumir uma atitude pretensamente redentora do passado no presente (ou talvez fosse melhor dizer do presente no passado?). Nela se destacam tanto a busca ansiosa e desesperada das origens e da pureza e a recusa daquilo que é concebido como derivação e cópia, quanto a tentativa idealizada de manter a essência intocada dos objetos definidos como exóticos. Em última análise, tal atitude se compromete com assegurar o resgate e o fortalecimento do patrimônio imaterial e

\footnotetext{
${ }^{8}$ Viajante e etnógrafo alemão que viveu dois anos entre os indígenas que habitam o entorno do Monte Roraima, marco da tríplice fronteira Brasil-Guiana-Venezuela, no início da segunda década do século XX, quando colheu as narrativas dos povos taurepang e arekuna, que serviram de base para Macunaíma, de Mário de Andrade. Para se referir a essa região localizada no extremo norte do Brasil e no sul da Venezuela, a literatura especializada do campo etnográfico/antropológico emprega o epíteto "região circum-Roraima".

${ }^{9}$ Talvez por mera coincidência, a acusação se dá nos mesmos termos do afamado artigo de Raimundo de Morais, mas agora sem sutilezas, de forma direta.

${ }^{10}$ Em Makunaima $\approx$ Macunaíma: contribuições para o estudo de um herói transcultural (2015), busquei responder algumas das questões acima elencadas: em se tratando da primeira, concluí que Makunaimî é o modo de designar próprio dos índios de Roraima e remete à corrente de circulação oral do lendário pemon; Makunaima (com K e sem acento) é a designação usada pelos índios e regionais de Roraima; Makunaíma (com K e com acento), por sua vez, remete à personagem do lendário tal qual coligida e apresentada pelo etnógrafo alemão Theodor KochGrünberg, Mitos e lendas dos índios Taurepang e Arekuna [Mythen und Legenden der Taulipáng-und ArekunáInadiarner]; Macunaíma (com C e com acento) remete ao herói da obra homônima de Mário de Andrade. Em se tratando da segunda questão, resta compreender que o compromisso de Mário de Andrade era com a configuração de um herói único e com um Brasil único, daí o farto uso da "desgeografização" como princípio construtivo; quanto à terceira questão, avento no presente ensaio uma resposta para ela. No quer diz respeito ao suposto "plágio" (questões "d" e "e") o próprio Mário de Andrade respondeu de forma exemplar em carta aberta endereçada a Raimundo Moraes e caso o leitor queira compreendê-la em maior profundidade remeto ao meu texto de 2015.
}

Rev. Bras. Lit. Comp. Niterói, v. 22, n. 39, pp. 26-36, jan. /abr. 2020 
material que se encontra supostamente em irremediável, iminente e alarmante perigo de extinção ${ }^{11}$.

Esse episódio fundador da minha atuação como postulante à função de crítico literário, espécie de rito inaugural ou de passagem, tornou latente e constante, desde então, a necessidade e a vontade de aprofundar estudos sobre os modos de permanência e atualização das textualidades indígenas e sobre a circulação e a transposição das textualidades da região circumRoraima para campos diversos das produções discursivas das humanidades. Também disparou o alerta para a necessidade de conjugar o saber-fazer a que me propunha como literato e a noção de laboratório científico - típico das práticas textuais do campo da etnografia. Demais, ajudou a perceber que o compromisso firmado com o trabalho de teorização e de crítica literária teria de se equilibrar, em certa medida, com aspectos e dimensões próprias às práticas da escrita etnográfica.

Decidi, então, mas ainda sem atinar completamente de que maneira fazê-lo, que construiria minha entidade teórica e crítica exatamente nesse espaço que parecia ser parcialmente interditado para forasteiros que passavam a ocupar uma função institucional no circuito de produção de pensamento crítico-analítico sobre a arte e a cultura literária dessa (des)importante periferia, a partir da qual desde então enuncio. O desafio a ser enfrentado tinha a ver com a realidade de como tornar possível e legítima minha participação no circuito da inteligência local, sem inviabilizar a participação num quadro de mais amplo espectro, que incluía as culturas brasileira, latino-americana e mesmo universal. Ou seja, ao mesmo tempo que tinha consciência de que por um lado essa posição era constrangida pelo sentimento de participação na cultura literária brasileira e ocidental, por outro, não podia esquecer que ela também estava irremediavelmente agora afetada pela capitalização dos reclames da diferença local - em suas dimensões amazonense, roraimense, étnica, etc.

Senti, então, na pele o modo como os deslocamentos migratórios propiciam relativizar determinadas certezas, senão também descobrir afinidades insuspeitas, como as que mais tarde pude perceber com relação a Roraima. Essa condição despertou o sentimento e a consciência de que para nós, os brasileiros, o Brasil não se constitui como um sentimento comum. $\mathrm{Na}$ verdade não há o Brasil; o que há são uns Brasis. A questão que se colocava, então, tinha a ver com a realidade de como relativizar o peso do passado que eu até então carregava, ao mesmo tempo em que ia adquirindo o peso novo do passado local, em que me inseria. Para tanto, a leitura de Dispersa demanda, de Luís Costa Lima (1981), auxiliou-me mantendo alerta para tentar não ceder jamais à "sensação ingênua ou fraudulenta [...] de [querer] não pertencer a nenhum grupo social", e de "parecer solto no espaço".

Dessa forma conjugadas, as vicissitudes da vida pessoal e da profissão fizeram com que questões que envolvem a circulação literária, os diálogos interculturais, a questão da representação do outro e dos problemas que envolvem a escrita de si e a escrita do outro fossem ganhando lugar de destaque entre minhas preocupações pedagógicas, estéticas, teóricas e críticas. Essas condições acabaram tornando "inevitável o confronto com problemas práticos, teóricos e metodológicos suscitados pelas relações estabelecidas entre arte, literatura, identidade, alteridade, apropriação, originalidade, derivação e trocas e transferências literárias e culturais." (Carvalho, 2015, p. 15).

\footnotetext{
${ }^{11}$ A antropologia anglo saxônica já tratou do problema de forma exemplar. Sobre a questão, sugiro a leitura do volume A escrita da cultura - poética e política da etnografia, organizado por James Clifford e George Marcus (2016). Trata-se de coletânea de artigos prestigiosos da década de 1980 e que, recentemente, foi traduzido para o português. O conjunto de artigos que compõem o volume marca uma tendência nova e instigante nos estudos sobre as sociedades, uma vez que centra a discussão nas relações mantidas entre a experiência etnográfica e a construção de narrativas em que se apresentam a análise e a interpretação de supostos "fatos" culturais.
}

Rev. Bras. Lit. Comp. Niterói, v. 22, n. 39, pp. 26-36, jan. /abr. 2020 
Trabalhando com uma minoria ora prestigiada ${ }^{12}$ no âmbito da prevalente política acadêmica da identidade, onde encontrar forças e reunir munição para recusar tanto a pretensão à neutralidade científica e a crença na ciência como realidade exterior, quanto a onda irracionalista que ora faz carreira como um rastilho de pólvora no nosso meio intelectual? Como não ceder à armadilha do esporte político-acadêmico preferido de nossa época, o modismo importado do extremismo "politicamente correto"? Enfim, como tentar fugir da importada e neocolonizadora moda conceitual estadunidense, que semeou no ambiente acadêmico brasileiro uma enxurrada de conceitos que funcionam como verdadeiros lugares comuns e que, conforme Bourdieu e Wacquant (2002, p. 15), são empregados para argumentar com, mas não para argumentar sobre: identidade, alteridade, apropriação, cultura, multiculturalismo, globalização e regionalismo, dentre outros? Como apontar e analisar as contradições desse campo sem me tornar extremamente inoportuno?

Nesse ambiente proliferaram outras questões de fundo: como desempenhar, com alguma dignidade, a função teórica e crítica no campo dos estudos literários quando a teoria vive, desde o final dos anos 1980, espécie de ocaso, senão mesmo uma crise crônica e generalizada? Como assumir uma posição marcadamente crítica num ambiente como o que ora impera no comezinho da vida acadêmica brasileira, em que, grosso modo, o elemento político-ideológico tende a se sobrepor à análise crítica? Como conciliar o reconhecimento, a importância e os avanços teóricos e sociais do modelo da diversidade, sem cair na armadilha de fazer proselitismo caseiro ou de me tornar colaborador, importador e adepto de produtos culturais próprios para o tecido social norte americano - a instância definidora da "nova Meca simbólica?" (Bourdieu \& Wacquant, 2002, p. 21)

Mais ainda: como manter estado de alerta para não compartilhar, de forma beata, dócil e útil, da convicção típica do século XIX que concebe que a explicação de todo fenômeno cultural deve sempre provir de uma origem longínqua e remota? (Capranzano, 2017, p. 100). Ou seja, como não cair naquele persistente apelo "pré-lapsariano" que tende a empreender uma leitura "aprisionada" das manifestações culturais das populações tidas como "tradicionais", e que as concebe enquanto "ilhas fora do tempo?" (Clifford, 2017, p.168). Enfim, como não ceder à tentação de impor ao índio aqueles mesmos lugares de devaneio utópico e idealizante ou de miséria e vitimização que tradicionalmente lhe são destinados nas produções da inteligência de quase todos os tempos?

Muitas são as nuances que envolvem as questões enfrentadas. E sendo assim, na senda de Sarlo (in: Moriconi, 2007, s. p.), vale indagar: "pode ainda a crítica ter alguma pretensão esclarecedora para cumprir, antes de seu tão anunciado desaparecimento na roda dos tempos, tragado pela disseminação infinita das fontes do sentido nas redes da informação eletrônica e da diversão a cabo?". Enfim, a teoria e a crítica literárias ainda podem ocupar algum lugar relevante em nosso meio e em nossos dias?

Diante do caso, fica avisado, caríssimo leitor, que não estamos em busca de solucionáticas fáceis, cegamente acolhedoras ou com tendência a refutações de quaisquer posições $a$ priori: estamos, isto sim, em busca fortalecer o exercício libertário de pensar no ambiente acadêmico - tão infenso a debates e tangências em nossos dias. Corroborando Ítalo Moriconi (2007, s. p.), somos da opinião de que "intelectuais são profissionais da inteligência", não meros "funcionários de um intelecto disseminado e dessublimado". [...] "Seja como for, creio que a função intelectual hoje implica em saber reconhecer a necessidade das forças atuando em meio à fantasmagoria das representações, desmascarando as ilusões da convicção". Demais, também comungamos do ponto de vista do argentino M. Topuzian (2014, p. 378), de que não se pode

\footnotetext{
${ }^{12}$ Desde 2002 trabalho com formação de professores indígenas na área de Comunicação e Artes, no curso de Licenciatura Intercultural do Instituo Insikiran de Formação Superior Indígena da UFRR.
}

Rev. Bras. Lit. Comp. Niterói, v. 22, n. 39, pp. 26-36, jan. /abr. 2020 https://doi.org/10.1590/2596-304X20202239fac 
simplesmente considerar a teoria como uma moda crítica esgotada, mas sim uma forma idônea de questionar profunda e consequentemente o nosso próprio labor.

Diante do quadro, resta ainda uma vez reafirmar o compromisso com a criação e consolidação de uma tradição teórica-crítica e literária produzida a partir do chão dessa região ainda pouco explorada pelo trabalho da inteligência analítica brasileira: a região circumRoraima. E assim sendo, talvez fosse o caso de concluir com a letra da canção "Destruindo a camada de ozônio" (do álbum Guentando a ôia, 1996), da banda pernambucana Mundo Livre S. A:"não espere nada do centro se a periferia está morta, pois o que era velho no norte, se torna novo no sul!".

\section{REFERÊNCIAS}

BERND, Zilá. Afrontando as fronteiras da literatura comparada: da transnacionalidade à transculturalidade. In: Revista Brasileira de Literatura Comparada, $\mathrm{n}^{\mathrm{o}}$ 23, 2013.

BOURDIEU, Pierre; WACQUANT, Loïc. Sobre as Artimanhas da Razão Imperialista. Estudos afro-asiáticos, Rio de Janeiro, v. 24, n. 1, p. 15-33, 2002 . Available from $<$ http://www.scielo.br/scielo.php?script=sci_arttext\&pid=S0101-546X 20020001 00002\&lng=en\&nrm=iso $>$. access on 15 May 2018. http://dx.doi.org/10.1590/S0101546X2002000100002.

CAMUS, Albert. A queda. São Paulo: Círculo do livro, 1986.

CARVALHO, Fábio Almeida de \& Jobim, José Luís. "Os caminhos de um herói transnacional”. In: Roberto Acízelo de Souza, Sílvio Augusto de Oliveira Holanda e Valéria Augusti. (Eds.) Narrativa e recepção: séculos XIX e XX. Rio de Janeiro/Niterói: de Letras/ EdUFF, 2010. p. 932.

CARVALHO, Fábio Almeida de. Makunaima $\approx$ Macunaíma: contribuições para o estudo de um herói transcultural. Rio de Janeiro: E-papers, 2015.

CLIFFORD, James \& MARCUS, George. (orgs.) A escrita da cultura - poética e política da etnografia. Rio de Janeiro: EdUERJ; Papéis selvagens, 2016.

FLÜSSER, Villén. Fenomenologia do brasileiro. http://www.iphi.org.br/sites/

filosofia_brasil/vilem_flusser_-_fenomenologia_do_brasileiro.pdf. Consultado em $01 \mathrm{de}$ out. 2019.

FOUCAULT, Michel. A escrita de si. In. FOUCAULT, Michel. O que é um autor? Lisboa: Passagem, 2009.

JOBIM, José Luís (ed.). A circulação literária e cultural. Oxford; Berna; Berlin; Bruxelas; Frankfurt; Nova York; Viena. Peter Lang, 2017.

LIMA, Luís Costa Lima. Dispersa demanda. Rio de Janeiro: Francisco Alves, 1981.

LONGXI, Zhang. The yet unknown World Literature. Revista Brasileira de Literatura Comparada, n. 32, 2017, p. 53-57.

MORICONI, Italo. A partir da nostalgia em Sarlo: aren(g)as, vocabulários, estratégias. 2010)http://pracriticar.blogspot.com.br/2007/11/italo-moriconi.html

PERLOFF, Marjorie. O multiculturalismo exerceu uma um efeito terrível sobre a nossa poética. https://revistacult.uol.com.br/home/entrevista-marjorie-perloff/. Acesso em 08/10/2018. 
RISÈRIO, Antonio. A utopia brasileira e os movimentos negros. São Paulo: Editora 34, 2007. SEN, Amartya. Identidade e violência: a ilusão do destino. Lisboa: Tinta da China, 2007. SEN, Amartya. Símbolo da nova terra. [No prelo]

Fábio Almeida de Carvalho é professor do PPg em Letras da Universidade Federal de Roraima, pesquisador do CNPq, e autor de artigos, capítulos e livros, entre os quais incluem-se Leituras e textos indígenas (EdUFRR, 2019) e Makunaima / Macunaíma - contribuições para o estudo de um herói transcultural (Rio de Janeiro: E- papers, 2015). Mais informações em http://lattes.cnpq.br/9997225424532634

Submetido em 03/11/2019

Aceito em 13/12/2019

Rev. Bras. Lit. Comp. Niterói, v. 22, n. 39, pp. 26-36, jan. /abr. 2020 